\title{
Cytotoxicity effects and apoptosis induction by cycleanine and tetrandrine
}

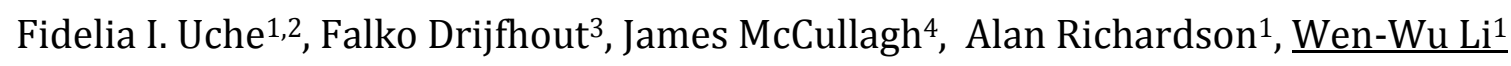

${ }^{1}$ Institute for Science and Technology in Medicine, Keele University, UK, ${ }^{2}$ Faculty of Pharmaceutical Sciences, University of Port Harcourt, Nigeria, ${ }^{3}$ Chemical Sciences Research Centre, Keele University, UK, ${ }^{4}$ Chemical Research Laboratory, University of Oxford, UK

Ovarian cancer remains one of the main causes of death in all gynecologic malignancies. ${ }^{1}$ Natural products continue to be important sources of clinically approved anti-cancer drugs. ${ }^{2-3}$ Triclisia subcordata Oliv (Menispermeaceae) is a medicinal plant traditionally used for the treatment of various diseases, ${ }^{4}$ including cancer, in West Africa. This study aims to evaluate the in vitro anti-ovarian cancer activities of the crude extracts and the isolated components in T. subcordata. The ethanol extract of T. subcordata and its fractions (crude alkaloids) were screened for in vitro anti-ovarian cancer activities on Ovcar-8, Ovcar-4, A2780, and Igrov-1 ovarian cancer cell lines using the Sulforhodamine B assay method to measure cell growth. Bioassay-guided fractionation using silica gel column chromatography and HPLC were used to isolate the bioactive compound, whose identity and structure was identified by NMR and LCMS techniques. Caspase and PARP cleavage assays were used to detect apoptotic activities. The effect of isolated pure compounds on cell cycle and apoptosis was analyzed by flow cytometry. Results: The crude alkaloids showed the strongest activity in cell growth assays on A2780 and Ovcar-8 cell lines $\left(\mathrm{IC}_{50}<2.4 \mu \mathrm{g} / \mathrm{mL}\right)$. A bisbenzylisoquinoline alkaloid-cycleanine was isolated using HPLC and identified by MS and NMR analyses. The $\mathrm{IC}_{50}$ values of cycleanine and tetrandrine (an alkaloid previously reported from this plant) ranged from 7 to $14 \mu \mathrm{M}$ on A2780, Ovcar-8, Ovcar-4 and Igrov-1 ovarian cancer cell lines. The $\mathrm{IC}_{50}$ of cycleanine on human normal ovarian surface epithelial cells was $35 \pm 1 \mu \mathrm{M}$ hinting at modest selectivity towards cancer cells. Both cycleanine and tetrandrine caused apoptosis as shown by activation of caspases $3 / 7$ (increased levels of caspases $3 / 7$ ) and cleavage of poly (ADP) ribose polymerase (PARP) to form PARP-I. The percentage of Ovcar-8 cells in subG 1 phase increased after exposure of

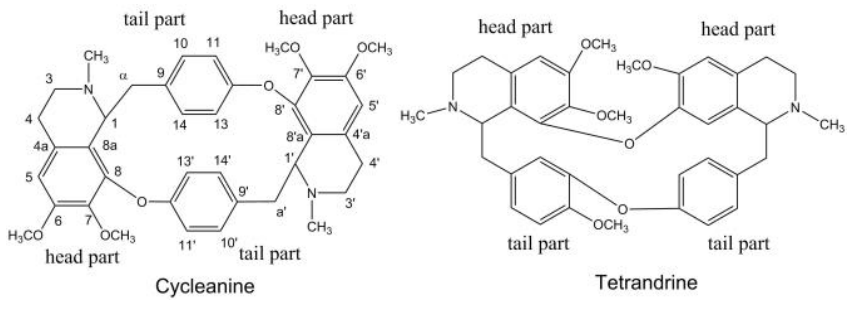
cycleanine and tetrandrine to cells for $48 \mathrm{~h}$ compared to control. In conclusion, cycleanine, like its isomer - tetrandrine isolated from Triclisia subcordata, could be a potential new antiovarian cancer agent acting through the apoptosis pathway.

Acknowledgements: We thank Nigerian ETF and NDDC for funding. We also thank Mr. John Clews for assistance in NMR measurements.

Keywords: Triclisia subcordata, cycleanine, tetrandrine, anti-proliferation, apoptosis, ovarian cancer

\section{References:}

[1] Siegel R, Naishadham D, Jemal A. Cancer statistics. CA: a cancer journal for clinicians 2013; 63: 11-30.

[2] Li WW, Johnson-Ajinwo OR, Uche F. Potential of Phytochemicals and their Derivatives in the Treatment of Ovarian Cancer. In: Collier BR, editor. Handbook on Ovarian Cancer: Risk Factors, Therapies and Prognosis. Nova Science publishers, USA, 2015, 155-180. 
[3] Johnson-Ajinwo OR, Richardson A, Li WW. Cytotoxic effects of stem bark extracts and pure compounds from Margaritaria discoidea on human ovarian cancer cell lines. Phytomedicine 2015; 22: 1-4.

[4] Abo KA, Lawal IO, Ogunkanmi A. Evaluation of extracts of Triclisia subcordata Oliv and Heinsia crinita (Afz) G. Taylor for antimicrobial activity against some clinical bacterial isolates and fungi. Afr J Pharm Pharmacol 2011; 5: 125-131. 